them. He always seemed to have his emotions under control, and only a twinkle revealed his sense of humour or a tightening of his jaw muscles his displeasure; he rarely displayed anger in his speech. He enjoyed the company of his friends, whom he chose with care, and he was fond of all sports, but golf, at which he had a single figure handicap, was his favourite form of recreation.

To a large circle of friends, colleagues, and to innumerable patients, his was a personality which will be remembered and mourned. To his widow and family we tender our deepest sympathy.

J.J.H.

\title{
CORRESPONDENCE
}

\section{RECESSION OF THE INFERIOR OBLIQUE}

\section{To the Editorial Committee of}

\section{The British Journal of Ophthalmology}

DEAR SIRS, - I have read with interest the article written by Mr. Ivor Lloyd on the subject of recession of the inferior oblique muscle, but I doubt whether the writer's view concerning the cause of overaction of the inferior oblique is as convincing as that of Chavasse. According to Chavasse* the "elevation in adduction" in a case of convergent strabismus free from obvious paresis of the ipsolateral superior oblique, or contralateral superior rectus, is due to the fact that, when an eye is adducted, the inferior oblique's elevating action is intensified because it is a stronger muscle than its direct antagonist - the superior oblique. C Chavasse's explanation is more likely than Mr. Llayd's. The latter argues that an effort of abduction which involves overaction of the inferior oblique is made in order to counteract excessive convergence.

I agree with the writer concerning the need for correcting both the horizontal and the vertical components in squint, but it is open to question whether there is any advantage in performing a recession of the inferior oblique rather than the simpler procedure of myotomy or myectomy.

It would have been more convincing if the case:results had contained not merely the statement that the overaction of the

* Chavasse, F. Bernard (1939).-Worth's Squint, 7th edition, London. 
inferior oblique had been corrected, but rather the actual measurements of vertical deviation, both before and after operation-including those made with the eyes in laevo- and dextro-version.

Yours faithfully,

T. Keith LyLE.

May 12, 1949.

Papers should be accompanied by a statement that they have not already been published elsewhere, and that they will not subsequently be offered to another publisher without consent of the B.J.O. Editorial Board.

All papers must be typewritten in double spacing on one side of the paper only, with a blank margin of $1 \frac{1}{2}$ inch. The Author's name and address should be plainly indicated. Illustrations should be detachable from the typescript, and numbered in sequence ; "and the upper edge of each should be marked "TOP" for the printer's guidance. Each illustration should be marked on the back with the author's name. References to the literature should be listed with the authors' names alphabetically arranged, and set out in the Harvard system, e.g., LANGLEY, J. N. (1919). J. Physiol., 53, 120. Information concerning reprinted copies will be despatched with galley-proofs to the authors of articles accepted for publication.

As we go to Press we regret to learn of the mic Surgeon at Hull Royal Infirmary. Also of Dr. George Mackay, formerly Lecturer on Ophthalmology in Edinburgh. University. Obituary notices will appear in our next issue.

Ophthalmological THE next General Meeting of the OphthalmoSociety of logical Society of Córdoba takes place on
Cordoba November 25 , next, for the purpose of reappointing the office-bearers. Those remaining in office are as ollows :-

Urrets Zavalia (hijo); Treasurer, Dr. Roqué A. Maffrand,

Any correspondence should be addressed to The Secretary, Calle 27 de Abril 255; Córdoba (R. Argentine).

AN exhibition for the blind and the partially blind has been arranged in the Science Museum, South Kensington, from June 11 to 21. This exhibition is not open to the general public, but the organisers will be pleased to welcome those who are specially interested in the welfare of the blind.

\section{Papers submitted for publication should be sent to :- The Secretary of the Editorial Committee, \\ British Journal of Ophthalmology, \\ Institute of Ophthalmology, Judd Street, London, W.C.1}

